\section{Poland steps up research into mining safety}

POLAND celebrated St Barbara's day, (4 December) - the traditional miners' festival - in the shadow of three major disasters that cost the lives of 66 Silesian miners in October. Not surprisingly, the official celebrations stressed the importance of mining safety. Speaking at Katowice, the mining centre of Silesia, party leader Edward Gierek, himself a former miner, called upon "all Polish scientists ... to develop research into greater safety in mining". At the same meeting the Minister of Mining, Wlodzimierz Lejczak, announced that this year Poland is spending some 15,300 million zloty on mining safety.

Coal accounts for $95 \%$ of Poland's energy needs and is a major hard-currency earning export, bringing in some $\$ 1,700$ million annually; total production now runs at some $\mathbf{2 0 0}$ million tonnes annually. However, Poland's mines are particularly hazardous. Recently, Dr Jerzy Matuszewski of the Central Mining Institute in Katowice told Nature that in virtually all Polish mines there is a considerable methane hazard. Moreover underground mechanisation is increasing the dust hazard, and the great depth of the pits - about $1000 \mathrm{~m}$ - exacerbates the risk of rock-falls.

Dr Matuszewski is director of the institute's own experimental mine appropriately named "Barbara" - where a network of galleries (5 km in all), provided a test-site for the study of gas explosions.

Researchers also study dust control at the "Barbara" site. The dust control section produces spectacular demonstrations of the almost instantaneous combustion of methane when mechanical cutters are used without the water spraying now obligatory in mines using such cutters. Less spectacular, but equally important, are the routine tests on the combustability of conveyer belts, the monitoring of surface movements, the design of protective clothing, and various anti-silicosis measures.

Mining safety research, in fact, extends far beyong those institutes specifically associated with mining. The Institute of Geophysics of the Polish Academy of Sciences, for example, is currently carrying out a geodynamic survey to attempt to predict earthquakes in mining areas. A special fire-extinguisher recently introduced in hard-coal mines was developed in collaboration with the airforce technical institute. And the Department of Electromagnetic Wave Theory of the Technological Institute of the Academy of Sciences have produced a

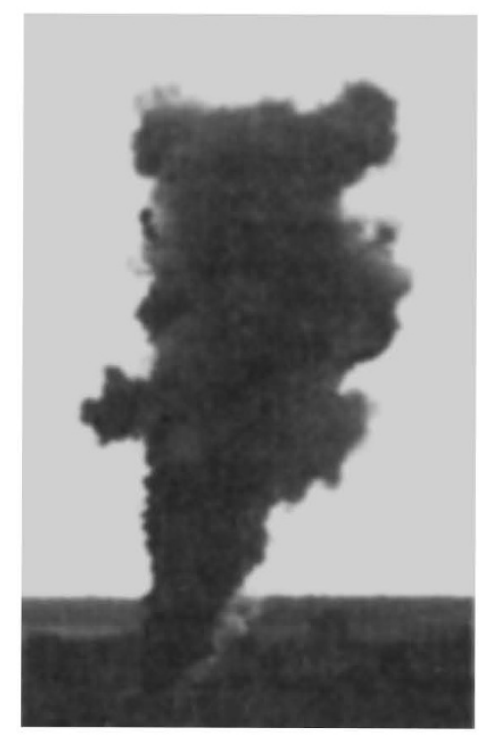

Experimental explosion: Poland stresses mining research after major pit disasters

system of radiocommunication for mines.

So much for the physical hazards. What about psychological stress? Although there are some psychological experiments going forward - mostly psychomotor studies little is said officially about the role of physchological stress in mining accidents. And no official statistics of day-to-day accidents are published - although 'unofficial' estimates place the 1978 fatality figure at around 180 . One mining official suggested that "production targets" were the greatest single cause of accidents - "but there is little can be done about that!"

Mr Gierek, in his own tribute to the miners' festival, spoke of the new "fourshift"' system (three shifts a day, plus one shift entirely off). This was officially introduced two years ago, is being implemented in an increasing number of mines, and is aimed at "improving our miners' working and living conditions". Mr Gierek failed to mention that all three of the mines involved in the October disasters had "four-shift" schedules.

\section{Computers can replace maths for scientists, says Soviet professor}

COMPUTERS must inevitably change the whole structure of mathematical training, from scientists down to schoolchildren, according to Professor Aleksandr Kitaigorodskii. Writing in the prestigious Soviet weekly, Literaturnaya Gazeta (No. 43,1979 ), he envisages a future with a small computer on every classroom desk, where pure mathematics will become a form of art and "culture", and problem solving will have virtually vanished from the academic syllabus. With the advent of the computer as “co-respondent”, says Kitaigorodskii, the long "marriage" of mathematics and science is ripe for "divorce".

His article is clearly intended as something more than idle futurology. A well presented "press campaign" is a standard Soviet gambit for informally airing a proposed major policy change. A few issues later, (no. 49), an article by Professor M Evgrafov of the Mathematical Institute of the Academy of Sciences of the USSR ostensibly presented a counterargument. This, however, while counselling caution in planning reforms, only served to reinforce the theme of mathematical irrelevance. Evgrafov claimed in particular that "not a single result obtained in pure mathematics" has had any practical applications for at least 50 years, while by that time " $90 \%$ " of all such results have now been completely forgotten; and even at the time of its discovery, the "most elegant mathematical result" will be understood by "not more than 100 persons". Since, moreover, so few people are capable of "creative mathematical work", he finds the current insistence on mathematical training in higher education and research instutites, "wanton", "rigid", and "useless".

As for problem-solving, he suggests that in the future this will become pre-eminently the domain of the programmer ("a person of middle-level qualifications") and only if the problem has been wrongly formulated will it be necessary to revert to the "tried

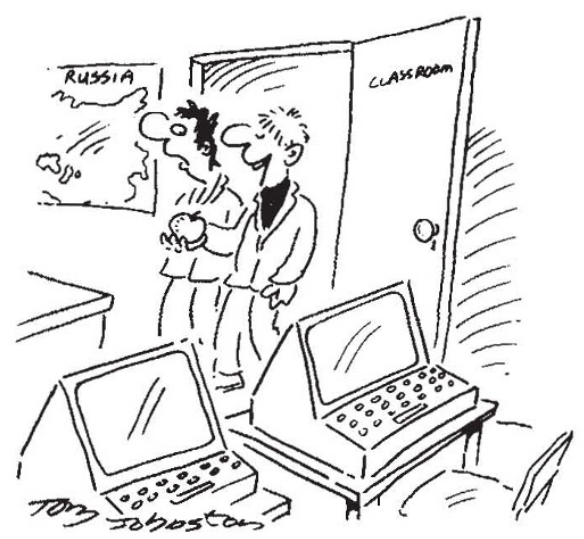

An apple for the programmer

and tested" method of the "Old Testament" - calling in a highly qualified mathematician.

More vehement counter-agruments have been reduced so far to small type at the foot of a column. They deal mainly with a computer's inability to "solve" anything, or, more specifically, to deal with continuous or infinitesimal processes.

A somewhat more original suggestion is advanced by $\mathbf{A}$ Badaev, a Candidate of Technical Sciences (roughly equivalent to a PhD) from Penza. Without the common language of mathematics, he says, science would soon be reduced to a state resembling "the well known Biblical legend of the Tower of Babel"'

Vera Rich 